\title{
Study of epidemiology, clinicopathological correlation, prognostic factors and management in squamous cell carcinoma of vulva
}

\author{
Chetana D. Parekh, Ruchi S. Arora*, Shilpa M. Patel, Pabashi Poddar, \\ Ava D. Desai, Meeta M. Mankad
}

Department of Gynaecologic Oncology, The Gujarat Cancer and Research Institute, Civil Hospital Campus, Asarwa, Ahmedabad, Gujarat, India

Received: 24 October 2018

Accepted: 28 November 2018

*Correspondence:

Dr. Ruchi S. Arora,

E-mail: drruchiarora@gmail.com

Copyright: () the author(s), publisher and licensee Medip Academy. This is an open-access article distributed under the terms of the Creative Commons Attribution Non-Commercial License, which permits unrestricted non-commercial use, distribution, and reproduction in any medium, provided the original work is properly cited.

\begin{abstract}
Background: Carcinoma of the vulva is rare cancer, pruritus is the most common and long-lasting reported symptom. It is found to be associated with HPV and HIV infection. Currently, a more individualized and less radical treatment is suggested. In this study we evaluated epidemiology, clinicopathological prognostic factors, HPV distribution and risk factors for metastases to lymph nodes. We also reviewed multidisciplinary clinical management carried out at our institute.

Methods: It is a prospective study of 25 biopsy proven cases of Squamous Cell Carcinoma of Vulva, treated at our center from September 2014 to September 2016. We collected the data regarding the clinical presentation, histological details, treatment given, survival and complications. HPV 16 and 18 testing were done using PCR method. Median follow up of the patients are for 24 months.

Results: The mean age of patients was 54.6 years. Commonest presentation was perineal itching (36\%). HPV 16/18 were positive in $25 \%$ of the patients. Radical vulvectomy with bilateral groin dissection was done in $14 / 25$ (56\%) patients. Among these 14 patients, $35.7 \%(5 / 14)$ has lymph node metastases, disease free survival was $63.6 \%$ and overall survival was $81.1 \%$ for median follow up of 24 months. About one third of the patient presented with locally advanced disease. Six (24\%) patients received only chemo radiation as a treatment.

Conclusions: HPV and HIV infection increase the risk of vulvar cancer. Individualization of treatment is necessary. The use of preoperative chemoradiation in locally advanced disease might have promising results in future.
\end{abstract}

Keywords: HPV infection, Overall survival, Radical vulvectomy with groin dissection, Recurrence, Vulvar cancer

\section{INTRODUCTION}

Vulvar cancer accounts for $5 \%$ of all malignancies of the female genital tract and is the fourth most common gynecologic cancer. Squamous cell carcinoma of the vulva is the most common category (95\%); followed by melanoma, sarcoma, and basaloid. ${ }^{1,2}$

This disease often occurs in postmenopausal women, primarily in the fifth and sixth decades. However, Carter et al. have also observed the occurrence of invasive vulvar cancer in younger premenopausal patients, with a trend for multifocal lesions. ${ }^{3}$

Many of these lesions are associated with human papillomavirus (HPV) infections.

Human papillomavirus type 16 has been the strain of virus most frequently associated with intraepithelial lesion and invasive carcinoma of the lower genital tract, including the vulva. HPV16 DNA can be isolated in 70$80 \%$ of vulval intraepithelial neoplasia (VIN) and in 10$50 \%$ of invasive lesions. ${ }^{4,5}$ VIN, including dysplasia and 
carcinoma in situ (CIS), is seen with increasing frequency in younger women.

This reflects a changing pattern of contemporary sexual behavior with increased frequency of HPV, HIV infection of the lower reproductive tract. ${ }^{6}$ Both invasive and intraepithelial carcinoma of the vulva is frequently associated with prior, concurrent, or subsequent neoplasia of the vagina and cervix. ${ }^{7}$ Vulvar cancer may be asymptomatic, but most patients present with history of itching, vulvar swelling or ulcer, which may or may not be painful. There is often a long-standing history of pruritus, which may be due to associated vulvar dystrophy.

Treatment for early stage vulvar cancer is surgery, which may be hemivulvectomy or resection of primary tumor or Radical vulvectomy with bilateral groin dissection. Adjuvant radiotherapy (RT) and/ or chemotherapy are administered for positive or close margins and positive inguinal lymph node metastasis. ${ }^{8,9}$ For locally advanced or metastatic vulvar cancer (FIGO IV) neoadjuvant or definitive chemoradiation has to be considered besides surgery. Owing to the low incidence of the disease, the level of evidence for different treatment modalities is poor. Lymphatic spread of vulvar cancer cells usually first affects the inguinal nodes. Metastasis in regional lymph nodes occur with a frequency of $6-50 \%$ and is the most important prognostic factor. ${ }^{9}$

Authors conducted this study to evaluate and analyze epidemiology, clinicopathological and prognostic factor, HPV distribution, risk factors for metastases to lymph nodes. This review also shows the different clinical management carried out at our institute and highlights the need for future trials.

\section{METHODS}

It is a prospective study conducted at Gujarat Cancer and Research Institute, Ahmedabad. A total of 25 biopsy proven cases of Squamous Cell Carcinoma of Vulva, treated at our center from September 2014 to September 2016 were included in this study. We have taken all patients who were referred to our institute for management during above mentioned period after confirming the histopathology report of Squamous cell carcinoma of vulva.

\section{Inclusion criteria}

- Those patients, who have been incompletely or inappropriately treated outside were included in present study to see the impact of improper management on survival.

\section{Exclusion criteria}

- Patients who did not complete the treatment
- Patient with histopathology report other than squamous cell carcinoma and those with distant metastasis (IVb).

Details regarding patient's age, clinical presentation, menopausal status, treatment given, complications, survival status and follow up were studied and documented. HPV 16 and 18 testing was done using PCR method either from the biopsy or from the main specimen after surgery. Information regarding grade, size, location, depth of invasion of tumor, lymph node involvement was gathered from histopathological reports. Patients were followed up for median 24 months. Since carcinoma of vulva is rare disease, we had less number of patients in each treatment group to use any statistical analysis.

\section{RESULTS}

Patient's age ranged from 30 to 80 years in present study, with the mean age of 54.6 years. Majority of the patient $(15 / 25)$ were between 50 to 70 years of age. Only 4 patients $(16 \%)$ were less than 40 years. Most of the patients, $21(84 \%)$ were menopausal while only 4 patients were regularly menstruating. Commonest symptom of presentation was perineal itching, 09/25 (36\%), followed by local swelling $07(28 \%)$ and $6(24 \%)$ ulceration.

Table 1: Distribution according to age, symptoms, risk factors, site of origin.

\begin{tabular}{|l|l|}
\hline Age (in years) & No of Patients (n=25) \\
\hline $30-40$ & $04(16 \%)$ \\
\hline $41-50$ & $08(32 \%)$ \\
\hline $51-60$ & $07(28 \%)$ \\
\hline $61-70$ & $02(08 \%)$ \\
\hline $71-80$ & \\
\hline Symptom & $09(36 \%)$ \\
\hline Perineal itching & $07(28 \%)$ \\
\hline Swelling & $06(24 \%)$ \\
\hline Ulcer in perineal area & $02(8 \%)$ \\
\hline $\begin{array}{l}\text { Postmenopausal vaginal } \\
\text { bleeding }\end{array}$ & $01(4 \%)$ \\
\hline Pain & \\
\hline Site of lesion & $5(20 \%)$ \\
\hline Labia majora & $3(12 \%)$ \\
\hline Labia minora & $5(20 \%)$ \\
\hline Both majora and minora & $3(12 \%)$ \\
\hline Clitoris & $9(36 \%)$ \\
\hline Locally advanced & No. of cases \\
\hline Risk factors & $10(40 \%)$ \\
\hline White lesions & $05 / 20(25 \%)$ \\
\hline HPV infection & $04(16 \%)$ \\
\hline Tobacco addiction & $02(08 \%)$ \\
\hline HIV Infection & $02(08 \%)$ \\
\hline Diabetes mellitus & $02(08 \%)$ \\
\hline $\begin{array}{l}\text { Lower genital } \\
\text { malignancy/dysplasia }\end{array}$ & $02(08 \%)$ \\
\hline VIN & \\
\hline &
\end{tabular}


Majority of the patients $9 / 25(36 \%)$ had locally advanced stage of carcinoma vulva. Most common site of involvement was labia majora $(20 \%)$ followed by labia minora $(12 \%)$ and clitoris (12\%). White lesion, $10 / 25(40 \%)$ over the vulva was the commonest predisposing factor. HPV DNA identification was done by PCR method in 20 patients, and 5/20 (25\%) were positive for HPV 16/18. Three out of these five patients were under 50 years of age $(60 \%)$. One case among HPV positive was having squamous cell carcinoma of cervix stage III B. Other predisposing factors in present study included tobacco addiction (16\%) and HIV infection (08\%). Both the HIV positive patient were also HPV positive and one of them had high grade vaginal dysplasia and VIN III (Table 1).

Total 16/25(64 \%) patient had surgical treatment in present study. 14/16 patient underwent Radical vulvectomy with bilateral groin dissection. Of these $2 / 14$ patient also had lower urethral dissection. Out of these 14 patients, 5/14 had only surgery (35.7\%), 6/14 (42.8\%) had post-operative radiotherapy, 2/14(14.2\%) had adjuvant chemo radiation, and one case $(7.1 \%)$ had lesion involving anal verge, received preoperatively chemo radiation to reduce the tumour size and then subsequently followed by surgery.

Out of these 14 patients who underwent Radical vulvectomy with bilateral groin dissection, 3 are lost to follow up and 2 died of disease. Both the patients died of disease had lymph node metastases in histopathology report of surgical specimen and one had multifocal disease. Recurrence occurred in $2 / 14(14.2 \%)$ patients. One patient has recurrence at local site and is on palliative radiotherapy. Other patient with recurrence has groin lesion after surgery and is on palliative chemotherapy.

Only radical vulvectomy, was performed in 2/16 patients as they had vulvar micro invasion on biopsy. One of these (1/2) patient had synchronous cervical carcinoma and received concurrent chemo radiation but died due to advanced cervical malignancy (local and distant) metastasis. Six out of twenty-five $(24 \%)$ patient received only chemo radiation as surgery was not possible due to locally advanced disease or stage III / IV disease or associated co morbid condition. In this group 2 patient are alive with residual disease, one patient has small residual disease after chemo radiation, in whom surgery was planned but patient refused due to risk of wound dehiscence and associated morbidity. Two patients died within 2 yrs of follow up.

One patient died of severe COPD and another died of advanced disease involving upper vagina, $2 / 6$ patients are lost to follow up. Three out of twenty-five (12\%) patient came with improper and incomplete management outside. Out of these two patients had only wide local excision and another patient had simple vulvectomy for very large $(>4 \mathrm{~cm})$ tumour of the vulva. They visited late to our institution with huge local recurrence and/or nodal metastasis.

Table: 2 Treatments and survival.

\begin{tabular}{|c|c|c|c|c|c|}
\hline Treatment & $\begin{array}{l}\text { No. of } \\
\text { patient }\end{array}$ & $\begin{array}{l}\text { No. of } \\
\text { patients alive } \\
\text { with disease* }\end{array}$ & $\begin{array}{l}\text { No. of } \\
\text { patients } \\
\text { died* }\end{array}$ & $\begin{array}{l}\text { No. of patients } \\
\text { lost to follow } \\
\text { up*** }\end{array}$ & $\begin{array}{l}\text { No. of patients } \\
\text { free of disease } * * * *\end{array}$ \\
\hline Surgery & 16 & & & & 8 \\
\hline $\begin{array}{l}\text { Radical vulvectomy with bilateral } \\
\text { groin dissection }\end{array}$ & 14 & & & & 7 \\
\hline Only Six & 5 & & & 1 & 4 \\
\hline Six and Radiation & 6 & 1 & 2 & 1 & 2 \\
\hline Surgery followed by chemo radiation & 2 & & & 1 & 1 \\
\hline Chemo radiation followed by Surgery & 1 & 1 & & & \\
\hline Radical vulvectomy & 1 & & & & 1 \\
\hline $\begin{array}{l}\text { Radical vulvectomy and radiation for } \\
\text { cervical cancer }\end{array}$ & 1 & & 1 & & \\
\hline Only chemoradiation & 6 & 2 & 2 & 2 & \\
\hline Suboptimal, irregular treatment & 3 & & 2 & 1 & \\
\hline
\end{tabular}

Of these 2 patients received chemo radiation but one did not take any treatment. In this group $1 / 3$ patient died of disease and one died due to infected node causing septicaemia. One patient with advanced malignancy died of COPD and other died of cervical malignancy, six patients did not take complete treatment and were lost to 
follow up. Hence only 17 patients were studied for median of 24 months for survival. Out of these 17 patients $12(70.5 \%)$ are alive and disease-free survival among these is $8 / 17(47 \%)$. Survival among the patient in whom radical vulvectomy with bilateral groin dissection was done is $9 / 11(81 \%)$ as out of 14 patients of surgery 3 are lost to follow up, and disease-free survival among this group is $7 / 11(63.6 \%$ ) (Table 2$)$.

Present study showed lymph metastases in 5/14(35.7\%) patient in whom surgery was done as primary treatment. Lymph node metastases increase with the size of tumor. No inguinofemoral lymph node metastasis were seen with tumor size $<2 \mathrm{~cm}$. Lymph node involvement increases with depth of invasion. No inguinofemoral metastases were seen up to $3 \mathrm{~mm}$ of depth of invasion. (Table 3).

Table 3: Lymph node involvement according to the size of lesion and depth of invasion.

\begin{tabular}{|c|c|c|}
\hline & $\begin{array}{l}\text { No. of patients } \\
(n=14)\end{array}$ & $\begin{array}{l}\text { Lymph node } \\
\text { positive cases }\end{array}$ \\
\hline \multicolumn{3}{|c|}{ Size of lesion } \\
\hline \multicolumn{3}{|c|}{$<1 \mathrm{~cm}$} \\
\hline $1.1-2 \mathrm{~cm}$ & 2 & \\
\hline $2.1-3 \mathrm{~cm}$ & 5 & 1 \\
\hline $3.1-4 \mathrm{~cm}$ & 5 & 2 \\
\hline$>4 \mathrm{~cm}$ & 2 & 2 \\
\hline \multicolumn{3}{|c|}{ Depth of invasion } \\
\hline Up to $1 \mathrm{~mm}$ & 5 & 0 \\
\hline $1.1-3 \mathrm{~mm}$ & 3 & 0 \\
\hline $3.1-4 \mathrm{~mm}$ & 2 & 1 \\
\hline $4.1-5 \mathrm{~mm}$ & 2 & 2 \\
\hline$>5 \mathrm{~mm}$ & 2 & 2 \\
\hline
\end{tabular}

In all 14 patients in whom surgery (radical vulvectomy with bilateral inguinofemoral dissection) was performed bilateral suction drains were kept preventing lymph edema. All patients received postoperatively thrombus prophylaxis and physiotherapy. None of the patient developed deep vein thrombosis. The mean postoperative stay was 12.8 days. Wound dehiscence was most frequently observed complication seen in 6/14 (42.8\%) patient. Less frequently observed complications were lymphocyst $1 / 14(7.14 \%)$, lymph edema $2 / 14(14.2 \%)$ and fever $2 / 14(14.2 \%)$ which were managed conservatively.

\section{DISCUSSION}

Carcinoma of the vulva is rare disease, mainly affecting elderly patient. ${ }^{1,2}$ Hampl et al from Dusseldorf reported that the vulvar cancers diagnosed in women under the age of 50 years has increased from $11 \%$ in the 1980 s to $41 \%$ in 2007 in their single institution study. ${ }^{10}$ In present study patient's age ranged from 30 to 80 years, and $16 \%$ were under the age of 40 years. This was comparable with study conducted by Lai $\mathrm{J}$ et al. Mean age in present study was 54.6 years reflecting the change in trend of epidemiology of vulvar cancer. ${ }^{11}$

According to Yetmen Ö et al itching is the first symptom of Squamous cell carcinoma of vulva. ${ }^{8}$ Alkatout study also shows that itching, ulcer, and swelling over the vulva are the main symptoms in vulvar cancer patient. ${ }^{12,13}$ Results of our studies also has similar findings, perineal itching in $9 / 25(36 \%)$, local swelling, in $7(28 \%)$ and ulceration in $6(24 \%)$ patients. Women with vulvar cancer also experience symptoms, such as, red, pink or white area that feels rough or wart-like surface pain or burning feeling while urinating, bleeding and discharge not associated with menstruation, an ulcer that lasts more than a month. ${ }^{13}$ White lesions was the most common presentation, 10/25 (40\%) patients in this study had white lesions. All these patients were more than 60 years of age. There are the 3 groups of white lesions described in the classification of dystrophies. Lichen sclerosus, lichen simplex chronicus and other dermatosis. In lichen sclerosis the skin of the vulva appears very thin, atrophic, and dry, resembling parchment. It is also white, with loss of pigmentation. Lichen simplex chronicus, is a chronic disease characterized by intense itching and scratching. In long-standing cases skin appears thickened and areas of hyperpigmentation and/or hypopigmentation may be present. It produces hyperkeratosis (excessive surface keratin) and creates a white, plaque-like area that is often strikingly white. Patients with lichen sclerosus and concomitant hyperplasia are at particular risk for malignant transformation. ${ }^{13,14}$

In present study 3 out of the $5 \mathrm{HPV}$ positive patients were relatively young, under 50 years of age $(60 \%)$. HPV are a large group of related viruses. HPV types linked with cervical, vaginal or vulvar cancer are known as high risk type and includes HPV 1618,33 as well as many other types. Infection with a high-risk HPV may produce no visible signs until pre-cancerous changes or cancer develops. ${ }^{5}$

According to some studies there are 2 types of vulvar cancer. One kind is associated with HPV infection and tends to occur in younger women as shown in present study. The other is not associated with HPV infection, is more often found in older women, and may develop from a precursor lesion called differentiated vulvar intraepithelial neoplasia. ${ }^{1,5}$

HIV infected individuals are predisposed to cancer of vulva due to immune suppression. In present study 2 patients out of 25 cases were HIV positive. ${ }^{6}$

Immunosuppression related to HIV infection or transplant medications is an important factor that has increased the incidence of vulvar dysplasia. Conley et al showed a 16fold increase in the development of vulvovaginal and perianal condylomata acuminata or intraepithelial neoplasia in a cohort of HIV-infected women compared with uninfected women. ${ }^{15}$ 
As in present study one of the HIV positive patients had vulvar carcinoma in situ with VIN and Vaginal dysplasia. This patient was also positive for HPV infection. The correlation between neoplasia of the low genital tract and HIV is so important that the Center for Disease Control and Prevention has included high-grade dysplasias and in situ carcinomas, in the classification of HIV, with the invasive cancer of the cervix considered as a condition defining AIDS.

Treatment of choice in squamous cell carcinoma of vulva is surgery, which may vary depending upon the size of the tumor and stage. Lesions that are $<2 \mathrm{~cm}$ in diameter and confined to the vulva, with stromal invasion $\leq 1.0 \mathrm{~mm}$ (FIGO stage IA) can be managed by Wide Local Exision only with a tumor-free margin all-around of at least $1 \mathrm{~cm}$. Groin node dissection, which may be avoided in these early stages, because the risk of lymph node metastases is negligible in this group. ${ }^{1,16}$ Though surgery is the treatment of choice, adjuvant treatment in form of preoperative or postoperative chemotherapy or radiation or both is also needed.

Radical vulvectomy with bilateral inguinofemoral node dissection is part of staging for carcinoma vulva and was done in majority of cases operated at our institute, $14 / 25(56 \%)$ underwent radical vulvectomy with bilateral inguinofemoral dissection. Only two patients had only radical vulvectomy as histopathology showed micro invasion. The primary objectives of less radical surgery are to reduce morbidity while maintaining high cure rates for vulvar cancers.

The complications associated with vulvar and inguinal surgery is relatively high and causes lot of morbidity. In present study disease free survival among these operated patients is $63.6 \%$ and wound dehiscence was $(42.8 \%)$ most common complication. Advanced vulvar cancer treated with preoperative chemo radiation undergo a less destructive surgery, so it is a better therapeutic option with an improved quality of life avoiding morbidity in form of permanent colostomy or urinary diversion. One case in present study with lesion involving anal verge received preoperatively chemoradiation to reduce the tumor burden and was subsequently followed by radical vulvectomy with bilateral groin node dissection.

Another patient had large tumor after chemo radiation the lesion became operable, but patient refused surgery. The concept of neoadjuvant chemoradiation followed by surgery is promising option in advanced vulvar carcinomas. Chemoradiation may downsize tumor volume, and hence help achieve resectibility of the tumor. $^{16}$ However; no randomized trials have been carried out to study this option. ${ }^{8,9,17,18}$

Many patients with vulvar carcinoma, especially in countries like India, present as advanced inoperable tumor, as in present study. Total nine (36\%) patients presented with very advanced staged and could receive only chemoradiation. In such patients and in others, whose co morbidities make them unsuitable for surgery, definitive chemoradiation are the possible options. ${ }^{17,18}$ In a GOG Phase II study, chemoradiation with weekly single-agent cisplatin showed clinical response in $66.8 \%$ subjects which is significantly promising. ${ }^{19}$ Even in present study advanced cases have received only chemo radiation.

Our patient received mainly carboplatin and paclitaxol but none had complete remission on this. Present study has shown that majority of the patients come in very late stage and they are mostly non-compliant. There are high numbers of patient who have not completed treatment or taken irregular treatment and follow up (24\%). This may be due to old age, illiteracy and/or poor socio-economic status as seen in study by Bhatla et al. ${ }^{20}$

The depth of invasion is defined as the measurement of the tumour from the epitheliostromal junction of the adjacent most superficial dermal papilla to the deepest point of invasion. ${ }^{9}$ Hacker et al., shows no lymph node metastasis in 34 patients where depth of invasion is $<1$ mm. ${ }^{21}$ Even in present study there are no lymph node metastasis up to $3 \mathrm{~mm}$ depth of invasion. Other factors that correlates with outcome include histopathology, tumour thickness, and the presence or absence of lymphovascular space invasion. ${ }^{22}$ These features are all predictive of lymph node metastasis. The outcome of vulvar carcinoma depends mainly on inguinal lymph node status and clinical tumour diameter. In present study there are no lymph node metastases up to tumour size of $2 \mathrm{~cm}$.

\section{CONCLUSION}

Vulvar cancer is less frequent gynecological malignancy and hence the number of patients in present study is small. HPV and HIV infection increase the risk of developing vulvar cancer. Individualization of treatment for all patients with invasive disease is necessary. Less radical procedure can be advised for selected patients with unilateral, unifocal tumors to reduce the postoperative morbidity and improve cosmetic appearance. Risk of groin lymph node metastases is extremely low among the patients with tumors less than $2 \mathrm{~cm}$ and no more than $1 \mathrm{~mm}$ of stromal invasion. The use of preoperative chemoradiation or definitive chemoradiation in patients with locally advanced disease might have promising results in future.

\section{Funding: No funding sources \\ Conflict of interest: None declared \\ Ethical approval: Not required}

\section{REFERENCES}

1. Ibrahim Alkatout, Melanie Schubert, Nele Garbrecht, Marion Tina Weigel, Walter Jonat, Christoph Mundhenke. Vulvar cancer: epidemiology, clinical 
presentation, and management options. Int $\mathrm{J}$ Women's Health 2015;7:305-13.

2. Siegel R, Naishadham D, Jemal A. Cancer statistics, 2013. CA Cancer J Clin. 2013;63(1):11-30.

3. Carter J, Carlson J, Fowler J, Hartenbach E, Adcock $\mathrm{L}$, Carson L, et al. Invasive vulvar tumors in young women: A disease of the immunosuppressed? Gynecol Oncol. 1993;51(3):307.

4. Ansink AC, Krul MR, De Weger RA, Kleyne JA, Pijpers $\mathrm{H}$, Van Tinteren $\mathrm{H}$, et al. Human papillomavirus, lichen sclerosus, and squamous cell carcinoma of the vulva: Detection and prognostic significance. Gynecol Oncol 1994;52(2):180.

5. Rakislova N, Saco A, Sierra A, Del Pino M, Ordi J. Role of Human Papillomavirus in Vulvar Cancer. Adv Anat Pathol. 2017;24(4):201-14

6. T. S. Mohan Rao, Sravani Sandhya Bellam, and P. Gurupuprasad. Vulvar invasive squamous cell carcinoma in a young patient with Human Immunodeficiency Virus-seropositivitivity. Indian J Sex Transm Dis AIDS. 2015;36(2):204-6

7. Siegler E, Segev Y, Mackuli L, Auslender R, Shiner M, Lavie O. Vulvar and Vaginal Cancer. Vulvar Intraepithelial Neoplasia and Vaginal Intraepithelial Neoplasia: Experience of a Referral Institute. ISR Med Assoc J. 2016;18(5):286-9.

8. Yetmen Ö, Eren MD, Ozdemir Z, Unal O, Mayadaglı A. The Prognostic Factors and Treatment Outcome of Squamous Cell Carcinoma of the Vulva: A Mono Institutional Study. JSM Clin Oncol Res. 2015;3(1): 1040 .

9. Mahner S, Jueckstock J, Hilpert F, Neuser P, Harter $\mathrm{P}$, de Gregorio $\mathrm{N}$ et al Adjuvant Therapy in Lymph Node-Positive Vulvar Cancer: The AGO-CaRE-1 Study. JNCI J Natl Cancer Inst. 2015;107(3):426

10. Hampl M, Deckers-Figiel S, Hampl JA,etal. New aspects of vulvar cancer: Changes in localization and age of onset. Gynecol Oncol. 2008;109(3):340-5.

11. Lai J, Elleray R, Nordin A, Hirschowitz L, Rous B, Gildea C, Poole J. Vulval cancer incidence, mortality and survival in England: age-related trends. BJOG. 2014;121(6):728-38.

12. Hunter DJ. Carcinoma of the vulva: a review of 361 patients. Gynecol Oncol. 1975;3(2):117-23.

13. Philip J. DiSaia. Noninvasive vulvar lesions An illustrated guide to diagnosis and treatment Dystrophies, vulvodynia, and other noncancerous lesion. December, OBG Management 2006:18(12):62-79.
14. Vulvar nonneoplastic epithelial disorder. ACOG educational bulletin number 241, 1997. American College of obstetrician and Gynecologist, Washington, DC.

15. Conley LJ, Ellerbrock TV, Bush TJ, Chiasson MA, Sawo D, Wright TC. HIV-1 infection and risk of vulvovaginal and perianal condylomata acuminata and intraepithelial neoplasia: a prospective cohort study. Lancet. 2002;12:(359):108-13.

16. Swarupa Mitra, Manoj Kumar Sharma, Inderjeet Kaur. Ruparna Khurana, Kanika Batra Modi, et al. Vulvar carcinoma: dilemma, debates, and decisions. Cancer Manag Res J. 2018;10:61-68.

17. Hoffman MS. Squamous-cell carcinoma of the vulva: locally advanced disease. Best Pract Res Clin Obstet Gynaecol. 2003;17(4):635-47.

18. Jeevarajan S, Duraipandian A, Kottayasamy Seenivasagam R, Shanmugam S, Ramamurthy R. Treatment Outcome of Carcinoma Vulva Ten-Year Experience from a Tertiary Cancer Centre in South India. Cancer Manag Res. 2018;10:61-8.

19. Moore DH, Ali S, Koh WJ, Michael H, Barnes MN, McCourt CK, et al. A phase II trial of radiation therapy and weekly cisplatin chemotherapy for the treatment of locally-advanced squamous cell carcinoma of the vulva: a gynecologic oncology group study. Gynecol Oncol. 2012;124(3):529-33.

20. Sharma DN, Rath GK, Kumar S, Bhatla N, Julka PK, Sahai P. Treatment outcome of patients with carcinoma of vulva: Experience from a tertiary cancer center of India. J Cancer Res Therapeut. 2010;6(4):503-7.

21. Hacker NF, Berek JS, Juillard GJ, Lagasse LD. Preoperative radiation therapy for locally advanced vulvar cancer. Cancer. 1984;54(10):2056-61.

22. Woelber L, Eulenburg C, Choschzick M, Kruell A, Petersen C, Gieseking F, et al. Prognostic role of lymph node metastasis in vulval cancer and implication of adjuvant treatment. Int $\mathbf{J}$ Gynecol Cancer. 2012;22(3):503-8.

Cite this article as: Parekh CD, Arora RS, Patel SM, Poddar P, Desai AD, Mankad MM. Study of epidemiology, clinicopathological correlation, prognostic factors and management in squamous cell carcinoma of vulva. Int J Reprod Contracept Obstet Gynecol 2019;8:223-8. 